INTERNATIONAL DESIGN CONFERENCE - DESIGN 2018

https://doi.org/10.21278/idc.2018.0542

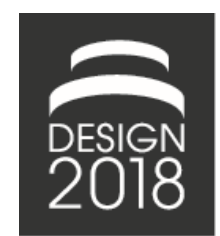

\title{
A NEW FRAMEWORK FOR CONSTRUCTION PROJECT DEFINITION STAGE
}

\author{
E. Pikas, J. Oehmen, L. Koskela and C. Thuesen
}

\begin{abstract}
One major reason for the poor performance of construction project delivery is related to the 'ill'performed project definition stage. The emphasis on rational decision-making and methods have stifled the creativity important to problem structuring and solution generation. Problem is in the poor conceptualization of the project definition stage in construction. Taking the design literature as starting point, the intent here is to clarify the underlying concepts and principles related to project definition stage, and propose a simplified prescriptive framework for the project definition stage.
\end{abstract}

Keywords: project definition, collaborative design, argumentative design, design theory, design cognition

\section{Introduction: Parallel challenges in the design and construction communities}

The abundance of problems in construction are well known, resulting in lost value to the customer. One of the key challenges in delivering new facilities is related to the poor briefing practices (Whelton and Ballard, 2002), which is also known by variety of other names, including design briefing, programming, front-end loading, and project definition and clarification, or an initial task. In this article these design activities are collectively named as the project definition stage. Due to poor performance of project definition stage, it often results in the dissatisfaction of customers and/or (potential) users. According to various researchers, one of the key reason has been in the poor conceptualization of design project definition stage. There is little evidence that merely rational methods of project definition result in better value to customers (Barrett et al., 1999; Pegoraro and de Paula, 2017).

The limitation of relying solely on rational methods was noticed much earlier in design literature. The first design methods movement was greatly influenced by the rationalist ways for conceptualizing design. However, the movement witnessed criticism by the early pioneers, including Christopher Alexander (1964) and J. Christopher Jones $(1992,1977)$. Their opposition emerged due to the little evidence of success for applying rational methods. In order to distinguish design from science, Rittel and Webber (1973) demarcated design task as subject to 'wicked problems'. Rittel and Webber (1973) suggested that the design problems are subject to different perspectives, values and objectives of various stakeholders involved in stating the requirements and designing, delivering and using the artefact. Buildings, and their delivery, are naturally complex systems. For example, due to the large diversity of interested parties extending from societal interests represented through government agencies and local authorities to the owners, (potential) users, designers, engineers, contractors and building managers.

For addressing the wicked nature of design problems in the project definition stage of construction projects, it is proposed that the ancient method of rhetoric, as universal method of inquiry (McKeon, 1966a), provides the required conceptual framework. It is important to note that this is not to argue that rational models are not needed or valuable, but rather that rhetorical (argumentative) and rational models 
of design are complementary, and that the proper synthesis of the two helps to develop a more complete framework for project definition. Regarding the rational method, the proto-theory of design is used as an underlying model for design conceptualization (Koskela et al., 2014).

As part of the proposed framework, the objective is also to define the domains, entities and relationships, which can serve the purpose of developing a theoretical and conceptual model for design coordination and management. Andreasen (2011) defined 'domains' as a set of dedicated views onto a product. These are used as the skeleton of a procedure for the product development/design. For example, the proposed framework would be useful for developing a common understanding among project parties as well as for developing design processes and digital design solutions.

For improving the project definition stage of construction projects, an assumption is made that ideas, concepts and principles can be transferred from design literature to the context of construction industry while taking into account the peculiarities of the constructions. For that, the problems in construction project definition stage are discussed; then the nature of design problems and design activities based on the design literature is addressed; and finally, a framework is synthesized, which will establish a baseline for future research for empirical testing, and further development.

\section{Design project definition stage in construction industry}

The design and delivery of facilities is often described as a complex process. Fischer et al. (2017) described that the complexity has three main sources: the increased technical complexity of the buildings; the multifaceted regulatory constraints; and the need to include variety of experts with specific understanding and knowledge. Bertelsen and Emmitt (2005) added that the client organizations should be seen as a complex systems due to the diversity of perspectives and interests. Vrijhoef and Koskela (2005) argued that construction production is subject to three peculiarities, including site production (i.e. organizing the production around the product dependent on outdoor conditions), temporary production organization (e.g. fragmented supply chain), and one-of-a kind product (e.g. design-to-order project-based production), adding to the complexity of construction projects. Furthermore, Pikas et al. (2015a) contended that designing is complex, not only because of the complexity within one domain, but because of interdependencies above all three domains: product, process and organization. The complexity of construction projects was the starting point for Barrett et al. (1999) to argue that little had changed in the project definition practices within the last 30 years. Using techniques derived from the grounded theory to study the briefing practices, Barrett et al. (1999) contended that the problem is not simply a poor implementation of the good project definition practices, but in the poor conceptualization of project definition stage (Barrett et al., 1999): "Too great an emphasis on rational decision-making may stifle the creativity important to any construction project and can certainly undermine the ability of practitioners and researchers to understand and effectively address the problems". Thus, Barrett suggested that a new, richer framework needs to be developed, taking into consideration the social dimension.

Several studies have dealt with the challenges in order to develop better concepts, methodologies, principles and tools for project definition. To name few, approaches to improve the project definition practices include: the development of the knowledge management framework (Whelton et al., 2003); inclusive/collaborative and dynamic briefing practice (Othman et al., 2004); stakeholder management (Ravik et al., 2016); management of (potential) user needs (Spiten et al., 2016); target value design (Miron et al., 2015; Ballard, 2006); workplace planning (Pennanen, 2004); quality function deployment and digitalization (Natee et al., 2016); and BIM facilitated studies of user needs (Eastman et al., 2011). Some of these have worked better and others not so well. However, there is a lack of conceptualization. 20 years later than Barret, Pegoraro and de Paula (2017) came to the similar conclusion that there are still limitations: "The findings indicate a lack of consensus about key concepts and about the coverage of requirements processing, lack of applied methods and lack of practitioners' knowledge".

Yet, it is of utmost importance as project definition is the stage when the expected building life value is established (Fischer et al., 2017). The high value building is the one that achieves its purpose; e.g. school promotes learning and hospital promotes healing. An explicit and common concept would allow transforming mental models into externalized models that can be shared among designers. Moreover, a consistent concept supports the development of computing technologies and helps avoiding mistakes 
due to the neglect of some domains. Similar aspects have been studied already in the design literature. The limitations of applying a solely rational approach to problem structuring were already noticed in the late 1960s and early 1970s.

\section{Concepts of design problems and inquiry from design literature}

In this section key concepts relevant for understanding design and the project definition stage are summarized. This question is addressed from two different perspectives, including the rational/formal and social/argumentative paradigms of design. Koskela and Ballard (2013) proposed that the prototheory of design and design rhetoric represent the models for technical (necessary) and social (plausible), object-oriented and subject-oriented conceptualizations of design respectively. The former is derived from the classical method for solving geometrical problems, appealing to logical, rational and technological reasoning (Netz, 2003; Koskela et al., 2014); and the latter is derived from the classical method for producing persuasive speeches, appealing to argumentative reasoning (McKeon, 1966a; Stumpf and McDonnell, 2002; Koskela and Ballard, 2013).

\subsection{Types of design projects and objectives}

One way to think of design projects is according to the type of innovation design projects are expected to introduce. Rational approaches are often concerned with introducing new means (solution principles, structures and/or properties) for given ends (function and performance requirements). Based on this view, design projects have been divided into routine (no new variables or ranges in values), innovative (variable value ranges are outside the normal space) and creative designs (new variables are introduced) (Gero, 1990).

Although argumentative approaches need to consider the form too, these views are primarily concerned with the effects that the designs have on its environment, including (potential) users, clients, organizations and societies (Fischer et al., 2017). This view acknowledges that designs are not passive objects, but form an active part of human living. For example, Goldhagen (2017) argued about how the built environment shapes human behavior, cognition and well-being.

Furthermore, different types of objectives have been associated with these two views, including the 'fit for purpose' and 'compliance to requirements' (Oakland and Marosszeky, 2017). 'Fit for purpose' is a measure of how well the artefact helps to achieve customer purposes. The 'compliance to requirements' is a specification of the product functions and performances to be met in building design projects. For example, the indoor quality of the office space must meet a certain level of service (Pikas et al., 2015b). It is argued here that the former corresponds to the argumentative and latter to the formal views of design conceptualization respectively.

\subsection{Requirements and constraints}

Although many overlapping terms, such as requirements, performance, constraints, objectives and preferences are used, the main function of these terms is the narrowing of the design space, the state space for possible design solutions (Gero, 1990).

Nair et al. (2011) divided the concepts related to the narrowing the design space into two: requirements and constraints. Requirements are a set of statements of objectives and functions on what the design must achieve or do (Cross, 2008). In the rationalist view, requirements can be defined objectively and in solution neutral form (Stumpf and McDonnell, 2002).

Nair et al. (2011) defined the design constraints as "relationships between design variables that restrict the range of possible values or a physical limit of one variable". Furthermore, constraints can be characterized by type and rigidity of the constraint. The latter distinguishes absolute constraints from flexible. Nair et al. (2011) described the following types of constraints, including time, financial, process, standardization and dimensional constraints.

However, in the argumentative view, design requirements and constraints are not objectively given, but need to be discovered through continuous process of framing and re-framing of the design situation (Halstrøm, 2016). The interrogation of original purposes and requirements can and often do lead to less costly alternatives, and therefore, changes in the initial specification of requirements and constraints 
(Whelton and Ballard, 2002). Thus, it is not just a matter of specifying the requirements and constraints based on the design problem assumed to be given, but continuous, cyclic and dynamic process of learning and re-learning, subject to the beliefs and values of designers.

\subsection{Classes of design problems}

In order to develop better methods of inquiry for project definition, we need to understand the nature of design problems. Design problems are often characterized as under-specified, vague or not being subject to systematization. This is due the lack of information in three aspects of the design problems, including underspecified start state, goal state and the transformation function from start state to the end state (Restrepo and Christiaans, 2004). Simon (1981) described these as 'ill-structured' ('ill-defined') problems. It is a problem whose structure lacks definition in some respect and cannot be solved in linear fashion; i.e. there are unknowns in respect to the design project ends (goals) at the outset of the design process. One of the reasons is that design problems include sub-goals that are often implicit at the outset (Purzer et al., 2018). The implication is that although the problem structuring occurs mainly in the beginning of the design process, it also reoccurs during the design process (Restrepo and Christiaans, 2004). Hence, distinguishing between the problem solving and problem structuring is not straightforward task.

However, the limitation of the conceptualization of 'ill-structured' problems is that it has neglected the active agenda of design problems dependent on the experiences, values and goals of participants involved; and focused on the passive agenda in terms of its organization and representation (Lloyd and Scott, 1994).

Based on the neo-positivist view (Buchanan, 1992), Rittel and Webber (1973) proposed another categorization of the design problems, including the wicked and 'tamed' problems. Rittel and Webber (1973) defined wicked problems as a "class of social system problems which are ill-formulated, where the information is confusing, and where the ramifications in the whole system are thoroughly confusing". Wicked problems have following properties (Rittel and Webber, 1973): no definitive formulation of a problem; no stopping rule; solutions are not true or false, but bad and good; no exhaustive list of admissible operations; for every problem there are many explanations depending on the designer's experience and knowledge; every wicked problem is a symptom of another; no definitive test; every problem is unique; and no room for failure. What this means is that there is inherent indeterminacy, open-endedness in the design process (Buchanan, 1992).

\subsection{Problem and solution-oriented reasoning}

It is generally agreed that although on a macro level, design might look like a progression from the problem analysis to the solution synthesis and evaluation, on a micro level, the structuring of the design problem does not occur in isolation of the possible design solutions. Halstrøm and Galle (2015) argued that "design problems and solutions stand in a chicken-and-egg relation of mutual dependency, and therefore in practice tend to evolve in parallel". That is, problem and solution are co-evolving (Lawson, 1980; Dorst and Cross, 2001; Cross, 2008). But the question is, how designers address the wicked problems?

Harfield (2007) distinguished between 'the-problem-as-given' and 'the-problem-as-taken'. He stated that the problem with the 'problem-as-given' view lies in the underlying assumption that problems of design are 'out-in-the-world-to-be-captured' and not influenced by personal preferences and desires of the designer. In the problem as 'taken', designers have an active role (Harfield, 2007): "... architects construct the problems they seek to solve while at the same time defining and limiting the solution possibilities available to them".

According to Lloyd and Scott (1994), the personal values, beliefs and experiences are the factors that influence designers' use of the problem or the solution-oriented strategies; i.e. whether designers focus on describing the abstract relations and concepts (problem oriented) or descriptions of the possible solutions (solution oriented). The question is whether designers progress systematically from problems, or jump to solutions or partial solutions before the full formulation of the problem (Restrepo and Christiaans, 2004). 
Formal conceptualizations of design, such as the 'systematic approach' by Pahl et al. (2007), lean towards the problem oriented strategies, while argumentative methods lean towards solution oriented strategies, such as the design model by Cross (2008). The latter is also what Lawson (1980) named 'analysis through synthesis'.

\subsection{Design reasoning: Formal and argumentative concepts}

Design reasoning has been considered as a prototypical case of human intelligence and cognition (Restrepo and Christiaans, 2004): "design requires devising future states of the world (goals), recognizing current ones (initial states) and finding paths to bridge both (transformation functions)". The importance of design reasoning was stated by Rittel (1987), who said that "studying the reasoning of designers becomes a way of attempting to understand how design happens - possible the only way". For aiding the design inquiry, designers use external representations, design prototypes as epistemic means to transform, organize and re-use the design knowledge (Gero, 1990). Within this process, designers use logic as well as creativity (Kroll and Koskela, 2017).

Formal studies of reasoning can be either logical or psychological, focused on form and rules, or content, and are developed from the perspective of individual designer. Formal conceptions of design emphasize that design thinking is concerned with something novel and useful, which is then concretized, explored and eventually evaluated (Cramer-Petersen and Ahmed-Kristensen, 2016).

Since C. S. Peirce, the logical types of reasoning have been divided into deductive, abductive and inductive inferences (Niiniluoto, 1999). The formal design concepts have defined design as an abductive process (Roozenburg, 1993; Kroll and Koskela, 2014; Kroll and Koskela, 2016) as it is the only method of inference that introduces new ideas. For example, Jones (1992) described this as a 'leap of faith'. Although there are other interpretations (Koskela et al., 2018), the two commonly held views on abduction include (Dong et al., 2015): abduction is the synthesis of complex and contradictory information, and abduction is reasoning from function to form. But as shown by different protocol studies, it is important to bear in mind that all types of reasoning are essential and used in the design process. Many design models have combined the three types of inferences into a three-stage process of inquiry (Jones, 1992; Roozenburg and Eekels, 1995; Cross, 2008; Cramer-Petersen and AhmedKristensen, 2016).

Unlike the rule based theories of reasoning, the cognitive theory of reasoning suggests that humans reason using mental models. These models are developed based on the perception, imagination or compression of the discourse (Johnson-Laird, 2006). In mental model theory (Johnson-Laird, 2006), it is suggested that humans infer through possibilities and decide about the validity of the idea by simulating the world based on the experience. Validity of the inference must hold over all the models of the premises to be accepted. In order to simplify the reasoning, humans focus on a subset of the possible models of multiple-model problems. For example, as suggested by Kroll and Koskela (2015), in the parameter analysis it is proposed that designer focuses on the individual design parameter at any given time in design.

In argumentative conceptualizations of design, the task of a designer is concerned with values and purposes embodied in the context and its circumstances (Stumpf and McDonnell, 2002). Since Rittel and Webber (1973) proposed that design problems are wicked, design scholars have become interested in studying argumentation as a form of design discourse (Buchanan, 1985). Cramer-Petersen and Ahmed-Kristensen (2016) argued that whether designers work alone or in groups, design involves issues and contradicting positions that are open and mutually dependent on each other. During design, these perspectives appear as speculation, argumentation, trade-offs and negotiation.

Within the context of argumentative conceptualizations of design, framing and reframing of problems have been considered particularly useful. The idea of framing, initially proposed by Schön (1984), appeals to the notion that the subject matter of designers exists within the problems and issues of specific circumstances (Buchanan, 1992). It stresses the dynamic, cyclic and unfolding nature of design discourse. Designers need to frame themes of the desired value in order to conceive solutions. However, the problems with the 'reflective' practices that have been pointed out, include the lack of formality and reliability of its vocabulary, and that the 'framing' concept has been developed from the perspective of the individual designer (Stumpf and McDonnell, 2002). Studying the individual designer's or design 
team's discourse has similarities to the reasoning types in their verbal disposition (Cramer-Petersen and Ahmed-Kristensen, 2016).

\subsection{Conclusions}

Within this section, the objective was to understand the key concepts of design inquiry from the perspective of two different views of design, including rational/formal and argumentative models of design. These two views represent the object-oriented (technical) and subject-oriented (social) conceptualizations of design. Proto-theory of design is concerned with the imagination, deliberation, construction and reflection on artefacts, while design rhetoric is concerned with argumentation of views for framing and re-framing of the design situation. However, these are not necessarily contradictory, but complementary. Design is a complex activity, where two views are tightly coupled that distinguishing one from another is often not possible. Key concepts related to the two different views are summarized in Table 1. Based on these concepts and two views, the aim is to develop a more comprehensive conceptualization of design project definition.

Table 1. Comparison rational/formal and argumentative models of design

\begin{tabular}{|c|c|c|}
\hline Design Concepts & Rational/Formal Models & Argumentative models \\
\hline Related strategies of inquiry & Proto-theory of design & Design rhetoric \\
\hline Types of design projects & Routine, innovative and creative & Types of effects \\
\hline Types of project objectives & Compliance to requirements & Fit for purpose \\
\hline Starting point & Problem-as-given & Problem-as-taken \\
\hline $\begin{array}{l}\text { Requirements and } \\
\text { constraints }\end{array}$ & $\begin{array}{l}\text { Requirements and constraints can be } \\
\text { defined objectively and in solution } \\
\text { neutral form }\end{array}$ & $\begin{array}{l}\text { Requirements and constraints need to } \\
\text { be defined based on the study of the } \\
\text { design situation and are value-laden }\end{array}$ \\
\hline Classes of design problems & $\begin{array}{l}\text { Ill-structured (ill-defined) versus } \\
\text { well-defined }\end{array}$ & $\begin{array}{l}\text { Wicked problems versus tame } \\
\text { problems }\end{array}$ \\
\hline Underlying assumptions & Linear/sequential and objective & Dynamic and subjective \\
\hline Strategies of reasoning & Primarily problem-oriented & $\begin{array}{l}\text { Primarily solution-oriented (analysis } \\
\text { through synthesis }\end{array}$ \\
\hline Categories of reasoning & $\begin{array}{l}\text { Necessary, based on the logical or } \\
\text { psychological study of reasoning } \\
\text { (mental models) }\end{array}$ & $\begin{array}{l}\text { Plausible, based on the logic of } \\
\text { discourse }\end{array}$ \\
\hline Primary types of reasoning & $\begin{array}{l}\text { Deduction, abduction and induction; } \\
\text { model-based reasoning }\end{array}$ & Argumentation \\
\hline Disciplinary scope & Individual designer & Individual designer or design team \\
\hline
\end{tabular}

\section{Construction of a conceptual framework for project definition stage}

In this section, before the suggestion of a framework for project definition, the underlying starting points are clarified. Most importantly, instead of leaning towards one or the other design paradigm, either technical or social conceptualizations of design, the aim is to synthesize the two different views.

\subsection{Two complementary design paradigms: Technical and social}

First, it is important to note that there are two different contexts of technical and social views, either referring to the process of designing or the artefact being designed. More specifically, former refers to the process of designing. The latter refers to the object and social setting that a new artefact, such as a building, introduces as a consequence of a design process. These two contexts are what Kroes (2002) proposed as a 'dual nature of artefacts'.

With respect to design process, Rittel (1984) proposed that design is a social process subject to different values, beliefs and presuppositions. Similarly, Bucciarelli (1994) argued for the importance of the social view of design. However, the difference is that for Bucciarelli (1994) these domains, including the object-oriented/technical as well as social views were considered complementary. The former, implying causality, gives direction to the social interaction within the design process subject to different views 
and interpretations of design team members. This view has been extensively discussed above in Section 3 , thus, the focus here is on the artefact as a means for creating a new social setting.

Social setting view of the artefact emphasizes the situatedness of the artefact. For example, Lurås (2016) proposed based on the concept of 'system of systems' that designers need to consider the 'system we design within' and 'system we design for' as systems related to the artefact's environment, while the 'system of design' is the artefact itself. The first is for example the business environment, the second is the building site and its users' needs, and the third is the building being designed.

Vermaas and Dorst (2007) clarified the social setting view of the artefact from the philosophical perspective and suggested the division of design conceptualization based the structural and intentional views, technical and social respectively. The technical view is a physicochemical description of objects and phenomena. The social conception of design is the activity based view of the artefact. The latter is why and what the client and users want to do with the artefact; i.e. descriptions of acts, mental states (purposes, desires) of humans as intentional beings.

The implication of the proposed clarifications by Vermaas and Dorst (2007) is that the transformation of purposes into requirements is mediated by the definition of use functions and properties. This means, purposes are first transformed into a set of human actions, and only then to the physicochemical dispositions of the artefact to make the actions with the artefact to be effective. This explains the function of planning and programming stage in the building design process, necessary to establish the scope of design work.

Furthermore, Vermaas (2013) proposed that the design reasoning about artefacts proceeds in terms of five key aspects: goal, (user) action, function, structure and behavior. Goals and actions of the users can be related to the social conception of design; and function, behavior and structure to the structural conceptions of design. Goal indicates the needs of the organizations and users motivated by the gap; action is a technical activity determining how users can realize their goals, forming a use plan for the artefact; functions are the modes of deployment of the artefact required to support the action; behavior is the required capacity, corresponding to the required functions; and structure is means to achieve the expected behaviors (Vermaas, 2013).

\subsection{Proto-theory of design and design rhetoric}

It is argued here that the two pillars of design, including the proto-theory of design and design rhetoric (Koskela and Ballard, 2013), provide the necessary conceptual framework for operationalizing the technical and social conceptions of design for project definition. Before continuing to explain the different concepts of proto-theory of design and design rhetoric, it is important to define the scope of the project definition stage for this study.

For the purpose of this work, the phases used in the Lean Project Delivery System (LPDS) are used as a starting point (Whelton and Ballard, 2002), but with one considerable difference. In the LPDS, which is a macro process model for project delivery, the project definition stage is concerned with three phases, including the definition of the project purpose, design criteria and design concept. However, for the purpose of this work, the user study is made as an explicit step, which in the original conceptualization of LPDS is subsumed under design criteria step.

\subsubsection{Proto-theory of design}

In the proto-theory of design, there are two types of problems to be addressed, whether a function (requirements) of an artefact can be utilized (theoretical analysis) and how the artefact can be constructed (problematic analysis). Depending on the novelty of the problem, design projects can be either routine, innovative or creative. Every design solution must comply with the requirements and constraints of the given problem, which can be defined objectively in solution neutral form. However, problems can be ill-defined or ill-structured, requiring the transformation of an initial problem to a new well-defined problem. Design in the proto-theory of design context progresses linearly from problem statement to the solution principle and from there to the solution embodiment. Design is primarily concerned what is necessary for solving the problem. The types of inferences moving the design between different states include in addition to the transformation also the regression (abductive in nature) and decomposition in analysis and composition, deduction and induction in synthesis. Design process is 
conceptualized from the perspective of individual designer as an internal argumentation with oneself. Typical design activities in the proto-theory of design include the identification of needs and requirements, generation of solution alternatives, development of solutions, and evaluation of and decision on these solutions. Thus, the proto-theory of design, proposed based on the ancient method of analysis, covers more or less the concepts relevant in the technical conceptualizations of design (Koskela et al., 2014; Pikas et al., 2017).

\subsubsection{Design rhetoric}

As oppose to the proto-theory of design, design problem is not assumed to be given, but is taken by the designer. Specifically, designer must study the given situation, different audiences (user, owner, local government and society) and establish a common ground (values, facts and presumptions) to choose the intention for producing effects on its audience. This selection of an intention is wicked in nature, that is, value laden. In this process, designers use different sources of inspiration (topoi) to develop a solution, which are subject to three different appeals: design must be useful (functional), desirable (appealing to all senses) by its audiences and usable for their use purposes. Design is considered dynamic and subjective in nature. Design reasoning in design rhetoric is plausible, focused on the development of arguments (design as argumentation). Design process can be conceptualized either from the perspective of the individual designer or design team. Design rhetoric can be also conceptualized as a process of collaborative knowledge creation. A model proposed by Nonaka and Takeuchi (1995) is instructive, including four processes: internalization (individual acquiring knowledge), socialization (individuals sharing knowledge), externalization (using knowledge in design activity) and combination (alignment of different knowledge sources). This is the design-as-knowledge-explication model. Thus, the design rhetoric, proposed based on the ancient method of rhetoric, covers most of the concepts relevant in the social/argumentative conceptualizations of design (Koskela and Ballard, 2013; Ballard and Koskela, 2013; Pikas et al., 2017).

\subsection{A new framework for the early design phases of construction projects}

Based on the concepts described in Section 3 and 4, Table 2 was developed to illustrate the framework for project definition, integrating the two views of design activity, including technical as well as social. This framework integrates different levels of design processes, including macro and micro.

The first row of the Table 2 indicates the context of design project, that is, the 'system we design within'. The purpose and user study design phases belong to the 'system we design for' and requirements and concept design phases to the 'system of design'. In following, the social as well as technical activities with respect to these phases are described. However, it is noted here that these models get interpreted according to the characteristics of each step in design project definition.

First, it is important to clarify the application of causal models to project definition. That is, in every step of the design project definition, decisions need to be made with respect to goal, user activity, function, structure and behavior. That is the case no matter of the design phase, the difference is in the level of decomposition and central locus of a particular step. This means that the design problem and solution are co-evolving, illustrated by the building information modelling deliverables in the table below.

In the social activity, which falls into the design rhetoric conceptualization of design, two models are required to describe the design process, including design-as-argumentation and design-as-knowledgeexplication consisting of four activities: internalization, socialization, externalization and combination. An alteration between individual and collective discoursing. These models describe the process of studying the design situation, audiences (universal, particular audience of one, and oneself) and selecting the intention. The latter connects other elements, including the transmission of rules (transferring best practices and patterns from previous experience to new design situation by using analogy); usage of the fundamental arguments (lines of argumentation, topoi); and invention and development of issues, requirements, ideas and alternatives (Pikas et al., 2017).

The object of the design communication is subject to three different appeals, involving interrelated qualities of useful (logos), desirable (ethos) and usable (pathos). Designers must skillfully blend these three elements in the design argument, to gain compliance to their ideas (Pikas et al., 2017). Thus, in addition to the co-evolution of a problem and solution, it also includes the co-evolution of audience. 
The technical conception of design is as important. Once the problem is clarified and the intention is selected, the task of the design team is to deliver the design by choosing the 'best' means to utilize the functions in a specific context, considering all users and designers' frames. In this process, building designers use tools such as the building information modelling to represent designs. In the technical activity, which falls into the proto-theory of design, design activity consists of four activities: identify, generate, develop and evaluate/decide.

Finally, it is important to elaborate on the different types of decision that need to be made in the different phases of design project definition stage. These are done at the different levels of building system decomposition (Fischer et al., 2017). However, these are considered here as illustrative and will be clarified in the future research.

Table 2. Simplified visualization of the collaborative framework for the construction project definition stage

\begin{tabular}{|c|c|c|c|c|}
\hline \multicolumn{5}{|c|}{ Project definition stage in Context: System we Design Within } \\
\hline \multirow[t]{2}{*}{ Design Step } & \multicolumn{2}{|c|}{ System we Design for } & \multicolumn{2}{|l|}{ System of Design } \\
\hline & Purpose & User Study & Requirements & Concept Design \\
\hline $\begin{array}{l}\text { Causal design } \\
\text { model }\end{array}$ & \multicolumn{4}{|c|}{ Goal, User activity, Function, Structure, Behavior } \\
\hline Social activities & \multicolumn{4}{|c|}{$\begin{array}{c}\text { Design-as-argumentation } \\
\text { Design-as-knowledge-explication: Internalization, Socialization, Externalization, } \\
\text { Combination }\end{array}$} \\
\hline $\begin{array}{l}\text { Technical } \\
\text { activities }\end{array}$ & \multicolumn{4}{|c|}{ Identify, Generate, Develop, Evaluate/Decide } \\
\hline Decisions & $\begin{array}{l}\text { Project, use, } \\
\text { building, } \\
\text { structure and } \\
\text { behavior type }\end{array}$ & $\begin{array}{l}\text { User goals, use } \\
\text { activities and } \\
\text { properties, zone/spaces' } \\
\text { types, space structure } \\
\text { and behavior }\end{array}$ & $\begin{array}{l}\text { Requirements for } \\
\text { building systems } \\
\text { (loads, internal } \\
\text { climate etc.) }\end{array}$ & $\begin{array}{l}\text { Principle Solutions } \\
\text { for Sub-Systems: } \\
\text { Material and Sub- } \\
\text { System Type }\end{array}$ \\
\hline Illustration of & Massing Model & Stacking Model & Req. Model & Concept Model \\
\hline BIM deliverables & $=\frac{5}{8}$ & & 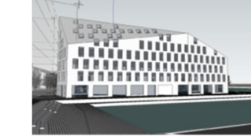 & 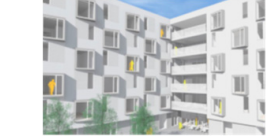 \\
\hline
\end{tabular}

\section{Discussion}

Generally, the field of construction lacks concepts and theories for project definition stage. The rational/technical conception of design has been the central focus in conceptualizing building project definition stage. However, this is not to argue that there have not been attempts to study design from the perspective of social dimension. But the ones, such as the one by Othman et al. (2004), do not address the underlying concepts for understanding the nature of design.

In order to have a more comprehensive theory for project definition stage, both perspectives, social and technical conceptions of design, must be addressed. Moreover, the ancient methods for solving geometrical problems and rhetoric, which have influenced the Western thought ever since their introduction (McKeon, 1966b; McKeon, 1968; Buchanan, 1985), provide the underlying conceptualizations for different strategies of inquiry. These together form the holistic design inquiry.

The developed framework will be used for empirical research in one of the largest construction companies in the Nordic countries. The framework is intended to be used for developing information and communication technologies for construction project definition stage. But the framework itself requires further clarification and comparison to existing conceptualizations of collaborative practices. The potential theories and concepts to consult will include the activity theory (including the sociocultural activity theory), communication constituted organization, actor-network theory, boundary objects, to name few. 


\section{Conclusion}

The aim in this research was to clarify the underlying concepts and principles related to the project definition stage, and to propose a framework for further study. Construction is known for its many problems, and one of the key issues has been the poor performance of project definition stage, which results in the dissatisfaction of customers and users. The problem is argued to be caused by the poor conceptualization of the project definition stage. In this study, it was suggested that the (general) design domain with its experiences going through the transition from emphasizing the rational methods to seeing problems as 'wicked' is a fruitful source of inspiration. The developed framework, combining technical and social conceptualizations of designing and design artefact, will form a baseline for future empirical research and comparison to existing theories and concepts. An explicit and common concept and framework would allow to transform mental models into explicit models, which in turn supports the development of computing technologies and helps avoiding mistakes due to the neglect of some domains.

\section{Acknowledgements}

This work was partially supported by funding provided by NCC and the MADE initiative. The authors gratefully acknowledge their support.

\section{References}

Alexander, C. (1964), Notes on the Synthesis of Form, Vol. 5, Harvard University Press.

Andreasen, M.M. (2011), “45 Years with design methodology”, Journal of Engineering Design, Vol. 22 No. 5 , pp. 293-332. https://doi.org/10.1080/09544828.2010.538040

Ballard, G. (2006), "Rethinking project definition in terms of target costing", Proceedings of the 14th Annual Lean Congress.

Ballard, G. and Koskela, L. (2013), "Rhetoric and design”, 19th International Conference on Engineering Design, Sungkyunkwan University, Seoul, Korea.

Barrett, P.S., Hudson, J. and Stanley, C. (1999), "Good practice in briefing: the limits of rationality", Automation in Construction, Vol. 8 No. 6, pp. 633-642. https://doi.org/10.1016/S0926-5805(98)00108-3

Bertelsen, S., and Emmitt, S. (2005), "The client as a complex system", 13th International Group for Lean Construction Conference.

Bucciarelli, L.L. (1994), Designing engineers, MIT Press.

Buchanan, R. (1985), "Declaration by design: Rhetoric, argument, and demonstration in design practice", Design Issues, Vol. 2 No. 1, pp. 4-22. https://doi.org/10.2307/1511524

Buchanan, R. (1992), "Wicked problems in design thinking", Design Issues, Vol. 8 No. 2, pp. 5-21. https://doi.org/10.2307/1511637

Cramer-Petersen, C.L. and Ahmed-Kristensen, S. (2016), “Argumentation and reasoning in design: An empirical analysis of the effects of verbal reasoning on idea value in group idea generation", Proceedings of the DESIGN 2016 / 14th International Design Conference, Dubrovnik, Croatia, The Design Society, Glasgow.

Cross, N. (2008), Engineering design methods: strategies for product design, John Wiley \& Sons.

Dong, A., Lovallo, D. and Mounarath, R. (2015), "The effect of abductive reasoning on concept selection decisions", Design Studies, Vol. 37, pp. 37-58. https://doi.org/10.1016/j.destud.2014.12.004

Dorst, K. and Cross, N. (2001), "Creativity in the design process: co-evolution of problem-solution", Design Studies, Vol. 22 No. 5, pp. 425-437. https://doi.org/10.1016/S0142-694X(01)00009-6

Eastman, C., Teicholz, P., Sacks, R. and Liston, K. (2011), BIM handbook: a guide to building information modeling for owners, managers, designers, engineers, and contractors, Wiley.

Fischer, M., Khanzode, A., Reed, D. and Ashcraft, H.W. (2017), Integrating Project Delivery, Wiley. https://doi.org/10.1002/9781119049272

Gero, J.S. (1990), "Design prototypes: a knowledge representation schema for design”, AI magazine, Vol. 11 No.4, pp. 26.

Goldhagen, S.W. (2017), Welcome to Your World: How the Built Environment Shapes Our Lives, HarperCollins.

Halstrøm, P.L. (2016), "Design as Value Celebration: Rethinking Design Argumentation”, Design Issues, Vol. 32 No. 4, pp. 40-51. https://doi.org/10.1162/DESI_a_00415

Halstrøm, P.L. (2017), "Rhetorical Tools for Discovery and Amplification of Design Arguments", Design Issues, Vol. 33 No. 1, pp. 3-16. https://doi.org/10.1162/DESI_a_00422

Halstrøm, P.L. and Galle, P. (2015), "Design as co-evolution of problem, solution, and audience", Artifact, Vol. 3 No. 4, pp. 3.1-3.13. https://doi.org/10.14434/artifact.v3i4.12815 
Harfield, S. (2007), “On design 'problematization': Theorising differences in designed outcomes”, Design Studies, Vol. 28 No. 2, pp. 159-173. https://doi.org/10.1016/j.destud.2006.11.005

Johnson-Laird, P.N. (2006), How we reason, Oxford University Press, USA.

Jones, J.C. (1977), "How my thoughts about design methods have changed during the years", Design methods and Theories, Vol. 11 No. 1, pp. 48-62.

Jones, J.C. (1992), Design Methods, John Wiley and Sons.

Koskela, L., Codinhoto, R., Tzortzopoulos, P. and Kagioglou, M. (2014), "The Aristotelian proto-theory of design", In: Chakrabarti, A. and Blessing, L.M.T. (Eds.), An Anthology of Theories and Models of Design, Springer, pp. 285-303. https://doi.org/10.1007/978-1-4471-6338-1_14

Koskela, L., Paavola, S. and Kroll, E. (2018), “The Role of Abduction in Production of New Ideas in Design”, In: Vermaas, P.E. and Vial, S. (Eds.), Advancements in the Philosophy of Design, Springer International Publishing, Cham, pp. 153-183. https://doi.org/10.1007/978-3-319-73302-9_8

Koskela, L.J. and Ballard, G. (2013), "The two pillars of design theory: Method of analysis and rhetoric", International Conference on Engineering Design (ICED 13), Sungyunkwan University, Seoul, Korea, August 19-22, 2013.

Kroes, P. (2002), "Design methodology and the nature of technical artefacts", Design Studies, Vol. 23 No. 3, pp. 287-302. https://doi.org/10.1016/S0142-694X(01)00039-4

Kroll, E. and Koskela, L. (2014), "On the problem of abduction in design", Design Computing and Cognition DCC'14, London.

Kroll, E. and Koskela, L. (2015), "Applying the proto-theory of design to explain and modify the parameter analysis method of conceptual design", International Journal of Design Creativity and Innovation, Vol. 4 No. 1, pp. 1-25. https://doi.org/10.1080/21650349.2015.1013568

Kroll, E. and Koskela, L. (2016), "Explicating concepts in reasoning from function to form by two-step innovative abductions", Artificial Intelligence for Engineering Design, Analysis and Manufacturing, Vol. 30 No. 02, pp. 125-137. https://doi.org/10.1017/S0890060416000020

Kroll, E. and Koskela, L. (2017), "Studying design abduction in the context of novelty", International Conference on Engineering Design (ICED 17), Vancouver, Canada, August 21-25, 2017.

Lawson, B. (1980), How designer think, The Architectural Press Limited.

Lloyd, P. and Scott, P. (1994), "Discovering the design problem”, Design Studies, Vol. 15 No. 2, pp. 125-140. https://doi.org/10.1016/0142-694X(94)90020-5

Lurås, S. (2016), "Systems Intertwined: A Systemic View on the Design Situation”, Design Issues, Vol. 32 No. 3 , pp. 30-41. https://doi.org/10.1162/DESI a 00397

McKeon, R. (1966a), "The methods of rhetoric and philosophy: Invention and judgment”, In: Wallach, L. (Ed.), The Classical Tradition: Literary and Historical Studies in Honor of Harry Caplan, Cornell University Press, Ithaca, NY, pp. 365-373.

McKeon, R. (1966b), "Philosophy and the development of scientific methods", Journal of the History of Ideas, Vol. 27 No. 1, pp. 3-22. https://doi.org/10.2307/2708305

McKeon, R.P. (1968), "Discourse, demonstration, verification, and justification”, Logique et Analyse, Vol. 11 No. 41/42, pp. 37-92.

Miron, L.I.G., Kaushik, A. and Koskela, L. (2015), "Target Value Design: The Challenge of Value Generation", Proceedings of the 23rd Annual Conference of the International Group for Lean Construction, Perth, Australia.

Nair, V., Howard, J., Culley, J., Dekoninck, A. and McAloone, C. (2011), "The Propagation and Evolution of Design Constraints: An Industrial Case Study", ICORD 11: Proceedings of the 3rd International Conference on Research into Design Engineering, Bangalore, India, January 10-12, 2011.

Natee, S., Low, S.P. and Teo, E.A. (2016), Quality Function Deployment for Buildable and Sustainable Construction, Springer. https://doi.org/10.1007/978-981-287-849-6

Netz, R. (2003), The shaping of deduction in Greek mathematics: A study in cognitive history, Vol. 51, Cambridge University Press.

Niiniluoto, I. (1999), "Abduction and geometrical analysis. notes on Charles S. Peirce and Edgar Allan Poe", In: Magnani, L., Nersessian, N.J. and Thagard, P. (Eds.), Model-based reasoning in scientific discovery, Springer, pp. 239-254. https://doi.org/10.1007/978-1-4615-4813-3_15

Nonaka, I. and Takeuchi, H. (1995), The knowledge-creating company: How Japanese companies create the dynamics of innovation, Oxford University Press.

Oakland, J.S. and Marosszeky, M. (2017), Total Construction Management: Lean Quality in Construction Project Delivery, Taylor \& Francis.

Othman, A.A.E., Hassan, T.M. and Pasquire, C.L. (2004), "Drivers for dynamic brief development in construction", Engineering, Construction and Architectural Management, Vol. 11 No. 4, pp. 248-258. https://doi.org/10.1108/09699980410547603 
Pahl, G., Beitz, W., Feldhusen, J. and Grote, K.-H. (2007), Engineering design: a systematic approach, Vol. 157, Springer. https://doi.org/10.1007/978-1-84628-319-2

Pegoraro, C. and de Paula, I.C. (2017), "Requirements processing for building design: a systematic review", Production, Vol. 27. https://doi.org/10.1590/0103-6513.212116

Pikas, E., Koskela, L. and Liias, R. (2017), "Design Management in a Design Office: Development of the Knowledge Base", 25th Annual Conference of the International Group for Lean Construction, Heraklion, Greece.

Pikas, E., Koskela, L., Thalfeldt, M., Dave, B. and Kurnitski, J. (2015), “Complexity in Designing Energy Efficient Buildings: Towards Understanding Decision Networks in Design", 23rd Annual Conference of the International Group for Lean Construction, Perth, Australia.

Pikas, E., Thalfeldt, M., Kurnitski, J. and Liias, R. (2015), "Extra cost analyses of two apartment buildings for achieving nearly zero and low energy buildings", Energy, Vol. 85, pp. 623-633. https:// doi.org/10.1016/j.energy.2015.03.026

Purzer, S., Moore, T.J. and Dringenberg, E. (2018), "Engineering cognition: A process of knowledge acquisition and application", In: Purzer, S., Moore, T.J. and Dringenberg, E. (Eds.), Cognition, metacognition, and culture in STEM education, Springer, pp. 167-190. https://doi.org/10.1007/978-3-319-66659-4_8

Ravik, K.M., Haddadi, A., Bjørberg, S., Foss, M. and Lohne, J. (2016), "Characteristics That Enhance Value for Users of Offices-Focus on Buildings and Stakeholders", 24th Annual Conference of the International Group for Lean Construction, Boston, USA.

Restrepo, J. and Christiaans, H. (2004), "Problem structuring and information access in design", Journal of Design Research, Vol. 4 No. 2, pp. 1551-1569. https://doi.org/10.1504/JDR.2004.009842

Rittel, H.W. (1984), "Second-generation design methods", In: Cross, N. (Ed.), Developments in design methodology, Wiley, pp. 317-327.

Rittel, H.W. (1987), "The reasoning of designers", International Congress on Planning and Design Theory, Boston, August, 1987.

Rittel, H.W. and Webber, M.M. (1973), "Dilemmas in a general theory of planning”, Policy sciences, Vol. 4 No. 2 , pp. 155-169. https://doi.org/10.1007/BF01405730

Roozenburg, N.F.M. and Eekels, J. (1995), Product design: fundamentals and methods, Vol. 2, Wiley, Chichester.

Roozenburg, N.F.M. (1993), "On the pattern of reasoning in innovative design”, Design Studies, Vol. 14 No. 1, pp. 4-18. https://doi.org/10.1016/S0142-694X(05)80002-X

Schön, D.A. (1984), The reflective practitioner: How professionals think in action, Basic Books, US.

Simon, H.A. (1981), The sciences of the Artificial, MIT Press, Cambridge, MA.

Spiten, T.K., Haddadi, A., Støre-Valen, M. and Lohne, J. (2016), "Enhancing Value for End Users — a Case Study of End-User Involvement”, 24th Annual Conference of the International Group for Lean Construction, Boston, $U S A$.

Stumpf, S.C. and McDonnell, J.T. (2002), "Talking about team framing: using argumentation to analyse and support experiential learning in early design episodes", Design Studies, Vol. 23 No. 1, pp. 5-23. https://doi.org/10.1016/S0142-694X(01)00020-5

Vermaas, P.E. (2013), "The coexistence of engineering meanings of function: four responses and their methodological implications", Artificial Intelligence for Engineering Design, Analysis and Manufacturing, Vol. 27 No. 3, pp. 191-202. https://doi.org/10.1017/S0890060413000206s

Vermaas, P.E. and Dorst, K. (2007), "On the conceptual framework of John Gero's FBS-model and the prescriptive aims of design methodology", Design Studies, Vol. 28 No. 2, pp. 133-157. https://doi.org/10.1016/j.destud.2006.11.001

Vrijhoef, R. and Koskela, L. (2005), "Revisiting the three peculiarities of production in construction", Proceedings of 13th International Group for Lean Construction Conference.

Whelton, M. and Ballard, G. (2002), "Wicked problems in project definition", Proceedings of the International Group for Lean Construction 10th Annual Conference, Brazil.

Whelton, M., Ballard, G. and Tommelein, I.D. (2003), "A knowledge management framework for project definition”, Journal of Information Technology in Construction, Vol. 7 No. 13, pp. 197-212.

Ergo Pikas, PostDoc

Technical University of Denmark, Management Engineering

Building 426, 2800 Kongens Lyngby, Estonia

Email: ekas@dtu.dk 